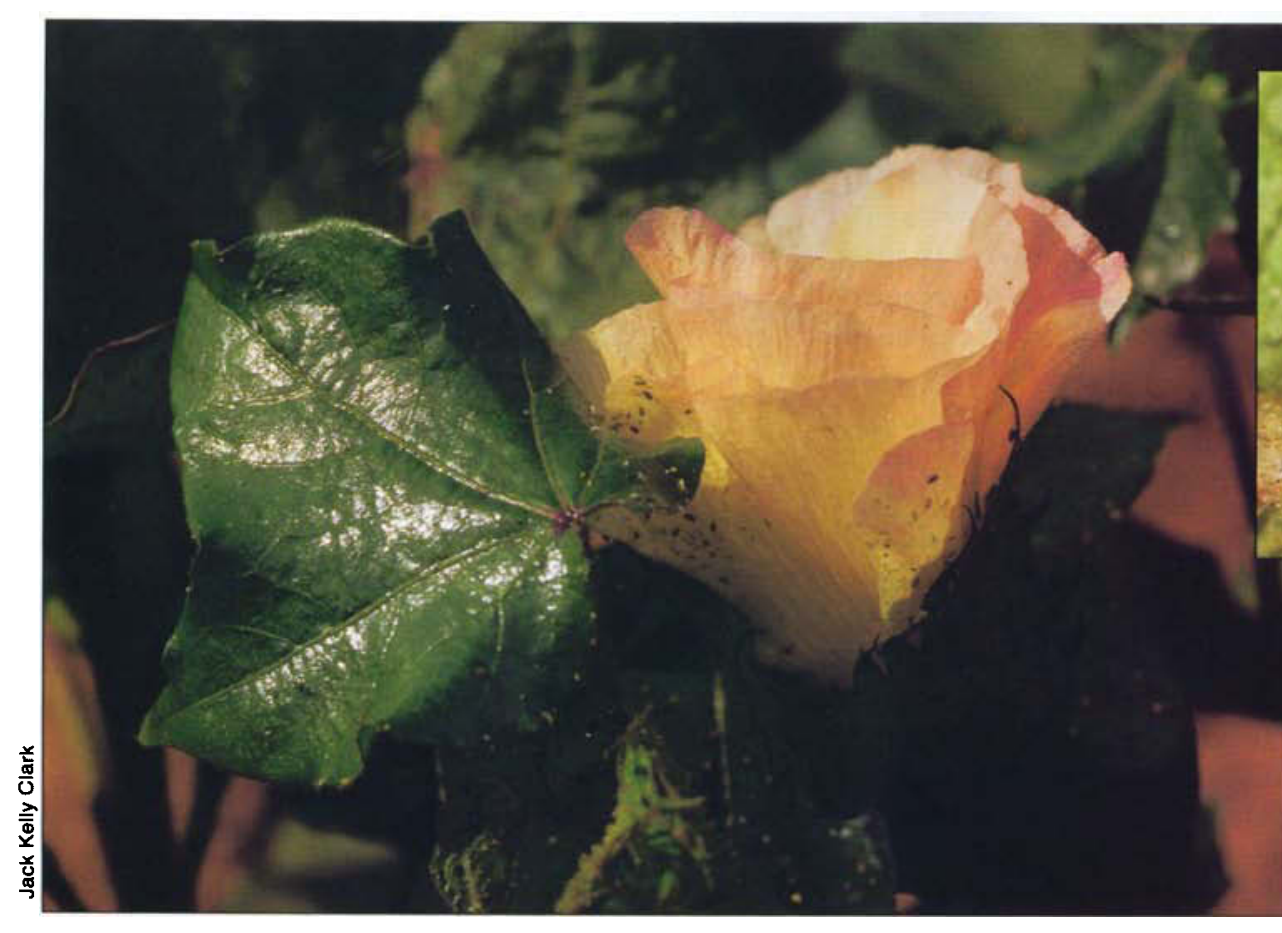

Over the past 10 to 15 years, the cotton aphid has escalated from an occasional pest to a severe pest to San Joaquin Valley cotton (two variations shown).

\title{
Cotton aphid emerges as major pest in SJV cotton
}

\section{Larry D. Godfrey a Jay A. Rosenheim $\square$ Peter B. Goodell}

During the 1990s, the cotton aphid (Aphis gossypii Glover) escalated from an occasional pest to an annual, severe pest of San Joaquin Valley (SJV) cotton. Although the cotton aphid is not a new insect in the SJV, the change in the bionomics of this pest dictated that new research efforts be directed toward its biology, damage thresholds and management. The 1980 s saw major shifts in agronomic practices. For example, the introduction of a plant growth regulator allowed growers to promote vigorous plant growth, rather than limiting growth and yield potential through the practice of water and nitrogen stress. Recent field research has shown that applying high rates of nitrogen to cotton plants increases cotton aphid reproductive rates and can create conditions favorable to aphid outbreaks. The new practice of promoting vigorous growth may have created an optimal host plant environment for cotton aphid reproduction and survival. In addition, the shift to using pyrethroids to control other arthropod pests has enhanced the buildup of cotton aphid populations. The severe aphid outbreak during the 1995 cotton growing season served as a focal point to bring the industry together to discuss the status of cotton integrated pest management and to plan future directions. Results of this effort include increased awareness, greater understanding of cotton aphid biology and improved pest management decisions.
$\mathrm{T}$ he cotton aphid (Aphis gossypii Glover) has escalated from an occasional pest to a severe pest during the last 10 to 15 years in the SJV. This has occurred in a series of steps. From about 1986 to 1991, the highest aphid densities were generally observed on cotton before squaring and again after boll opening. In 1992, high aphid densities developed midseason (July and August). This trend continued and reached a maximum in 1995 and 1997, when the cotton aphid was recorded as one of the most economically important arthropod pests of SJV cotton, replacing the traditionally important pests such as spider mites (Tetranychus spp.) and lygus bugs (Lygus hesperus). In 1997, cotton aphids in California cotton caused an estimated $\$ 34$ million in crop loss and another $\$ 38$ million in control costs. Overall, insect and mite pests in California cotton in 1997 caused an estimated $\$ 66$ million and $\$ 167$ million in crop loss and control costs, respectively. During 1998 and 1999, cotton aphid outbreaks were moderate and spotty; however, unusual weather patterns (El Niño and La Niña) were an overriding factor in SJV cotton production.

The cotton aphid is not a new insect in the SJV; Swift in the 1950s reported on the biology of this pest (Swift 1958). Cotton aphid outbreaks, especially in 
the cotton production area in eastern Tulare County, have occurred sporadically. However, changes in the bionomics and importance of this pest required that updated research be conducted on its biology, damage thresholds and management. Reasons for the "emergence" of cotton aphid as a key pest may be linked to changes in cotton production practices and in insecticide use patterns.

The 1980s saw major shifts in agronomic practices due to improved varieties and an emphasis on yield. The introduction of more determinate fruiting varieties resulted in a more compact growing season. During the same time, mepiquat chloride was introduced to control vegetative growth and improve fruit retention. The introduction of this plant growth regulator allowed growers to promote vigorous plant growth, rather than limiting their growth and yield potential through the practice of water and nitrogen stress. Recent field research has shown that water stress to cotton plants depresses cotton aphid reproductive rates and can cause heavy mortality of reproductive adults, and that aphid reproduction is enhanced on nitrogen-rich plants. This new crop management practice - of developing vigorously growing plants during the early- and midseason - may have created an optimal host plant environment for cotton aphid reproduction and survival. In addition, the shift to new chemical classes, specifically synthetic pyrethroid materials, to control other cotton arthropod pests has enhanced the buildup of cotton aphid populations.

\section{Cotton aphid biology}

With the initial outbreaks of aphids in cotton in 1986 and 1987, there was some uncertainty regarding the species involved. Rosenheim et al. (1994) identified the pest as Aphis gossypii and clarified that the cotton aphid exists as several phenotypes. The color variation extended from light yellow to green to dark green to black.

Nymphal aphids that are developing into winged or alate adults (alatiform nymphs) may also be amber colored, and some alatiform nymphs secrete white, powdery wax on their bodies. Dark cotton aphids (dark green to black) were found to develop more rapidly, give birth to more offspring, and grow larger than light (light yellow) aphids. Dark cotton aphids were also more tolerant of pesticides. Therefore, the dark aphids were implicated in the population explosions in the field. In a laboratory study, the factors associated with the production of dark morph aphids were identified as cooler temperatures, shorter day lengths and nutrient-rich host plants (Rosenheim et al. 1994). However, the influence of these factors and the role of the aphid phenotypes in cotton aphid population dynamics in the field have not been clearly elucidated.

Knowledge of cotton aphid biology during the winter (off-season period for cotton) is important in designing alternative management plans. Can management methods that would positively influence aphid management in cotton be implemented, such as releases of natural enemies or the destruction of weed hosts? Studies concentrating on the winter and early spring periods have shown that the sexual phase of the cotton aphid seasonal life history occurs on pomegranates. Alate males, oviparae (female aphids that mate and produce eggs), eggs and fundatrices (asexual female aphids that develop from eggs) were all found on this plant species. Winter annual weeds and citrus were also identified as hosts for overwintering asexual cotton aphids, but at much lower densities than the sexual forms found on pomegranates.

\section{Economic thresholds}

The development of treatment thresholds was a primary emphasis during the past 10 years of cotton aphid research in California, as no experiments had previously been conducted to establish the impact of cotton aphids on cotton plants grown under California conditions.

Rosenheim et al. (1997) showed that cotton can fully compensate for aphid infestations during the pre-squaring stage. The ability of early-season cotton to compensate fully for aphid feeding, and the generally short dura- tion of these early-season aphid infestations (because natural enemies attack them), suggested that early-season aphids should be viewed as "non-pests." In a limited region of the SJV, early-season aphid populations may persist, but in most of the valley a conservative treatment approach, such as not treating with insecticides and waiting for natural enemies to decimate the populations, is warranted.

During the cotton squaring and boll-filling period, cotton aphids compete directly with the cotton plant's reproductive structures for energy. The phloem-feeding aphids compete for the photosynthates along with the developing cotton bolls. Severe aphid feeding can result in smaller or fewer bolls per plant, reducing yield. Research by Godfrey and coworkers (1997) supported a treatment threshold of 50 to 100 aphids per leaf (fifth main-stem node leaf) for 7 to 10 days.

Following boll-opening, cotton aphids have the potential to deposit honeydew (excrement) on the exposed cotton lint. This threat is very serious for the cotton industry because sooty mold grows on honeydew, staining the fiber, and the stickiness of the honeydew gums up harvesters and processing equipment in gins and textile mills. A treatment threshold of 10 to 15 aphids per leaf is supported by Rosenheim's research and others.

\section{Biocontrol strategies}

Several studies have been conducted over the last 10 years on various aspects of natural control of cotton aphids in the SJV. Biological control is an important natural control measure for several arthropod pests of SJV cotton. Rosenheim et al. (1997) showed that predators and parasitoids effectively reduced aphid populations on pre-squaring-stage cotton. However, during the mid- and late season, biological control of the cotton aphid is generally poor; at this time, the community of natural enemies found on cotton is dominated by generalist predators, primarily lacewings and predatory bugs such as big-eyed bugs, minute pirate bugs and assassin bugs (Cisneros and Rosenheim 1997). Although lacewings can, when tested 


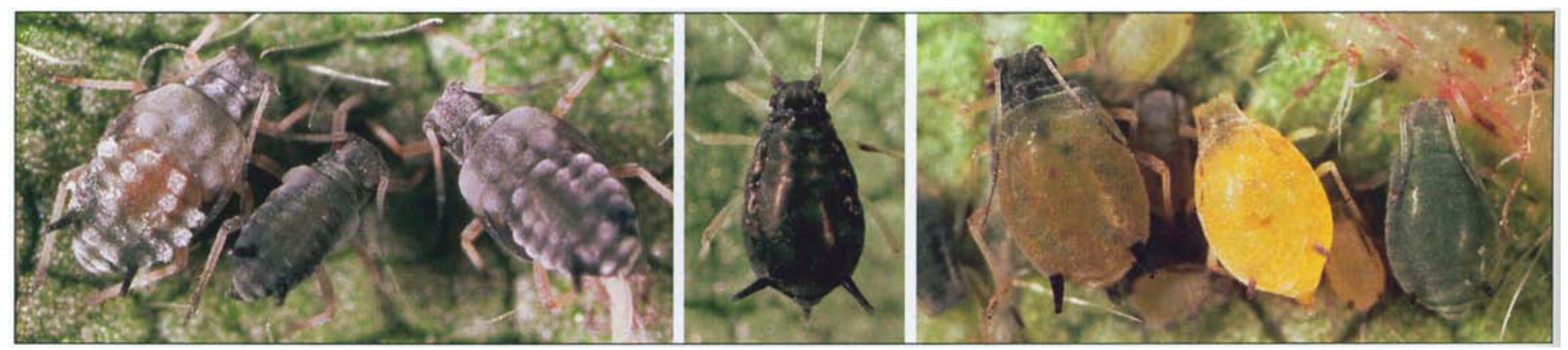

The cotton aphid exists as several phenotypes. The color variation extended from light yellow to green to dark green to black. Photos and digital composite by Jack Kelly Clark.

alone, suppress aphid populations effectively, lacewings are themselves suppressed by the predatory bugs, which eat the lacewing larvae. Because the predatory bugs eat relatively few aphids, overall suppression of aphid populations by the predatory insect guild is weak. Work is ongoing to expand the complex of natural enemies (primarily parasitoids) of cotton aphid in California. Exotic species have been imported by California Department of Food and Agriculture personnel, who have been releasing the natural enemies into SJV cotton. The survival, role and effectiveness of these new organisms are yet to be determined.

The susceptibility of state-approved California Acala cotton cultivars to aphid population development was evaluated at the onset of cotton aphid outbreaks in the early 1990s. Some slight differences were found, although the most commonly grown varieties were equally susceptible. As the range of cotton varieties grown has increased with the recent introduction of California Upland varieties, efforts to compare varietal susceptibility have been reinitiated.

\section{Insecticide control}

Insecticides are a primary means of managing mid- and late-season cotton aphid infestations. Organophosphate, carbamate, organochlorine,

chloronicotinyl and diamidide insecticides are all used to control aphids in California. Aphid control with insecticides can be very good; however, insecticide efficacy has often been erratic. Genetic-based insecticide resistance is common in the cotton aphid. Grafton-Cardwell (1991) identi- fied resistance to several organophosphate insecticides and to endosulfan in the mid- to late 1980s in the SJV. In the early 1990s, cotton aphids in California developed resistance to bifenthrin. In 1996, Grafton-Cardwell found that $83 \%, 71 \%$ and $42 \%$ of the aphid populations bioassayed were resistant to bifenthrin, endosulfan and chlorpyrifos, respectively. These data were collected at the peak of the aphid outbreak when selection pressure was greatest (Grafton-Cardwell et al. 1997).

\section{Influence of cultural practices}

Changes in the cotton agroecosystem and cultural practices were theorized to be part of the explanation for the increased importance of cotton aphids. Conversely, management strategies could be improved by understanding these effects. Higher aphid populations have consistently been seen on late-planted cotton (May) compared with early-planted cotton (April). Higher levels of nitrogen in the lateplanted cotton at some key point (for aphid buildup) in the season appears to be involved in this increase in aphid levels. Godfrey and coworkers showed that, in 1997, aphid populations averaged approximately 300 per leaf on plants fertilized with 200 pounds nitrogen per acre and 75 per leaf on plants with 75 pounds nitrogen per acre. Aphid densities were monitored in 1998 and 1999 in 15 large plots. Nitrogen response tests were conducted in grower fields, and higher aphid numbers were seen in all eight locations, with discernible aphid populations in the 200 versus 50 pounds nitrogen per acre treatments (Godfrey et al. 1999). Balancing the needs of the cotton crop for maximum production with the level that mitigates aphid population buildup remains an unresolved challenge.

Nitrogen level in the plant also influences aphid susceptibly to insecticides. Clonal cotton aphids, which developed on plants fertilized with 200 pounds nitrogen per acre, were more resistant to bifenthrin, endosulfan, chlorpyrifos, carbofuran and imidacloprid (insecticides from five different chemical classes) than aphids feeding on plants fertilized with 50 pounds nitrogen per acre. The higher levels of nitrogen affected the phenotypic response of the aphids and resulted in a higher number of dark morph aphids, which were shown to be incrementally more resistant to these insecticides compared with light morph aphids produced on the same plant.

The use of pyrethroid insecticides on SJV cotton was 20,169 pounds active ingredient (AI) in 1990 and peaked in 1995 at 59,404 pounds $\mathrm{AI}$ in 1995. The primary target pest has been Lygus hesperus and these products have been very effective on them. Aphid population increases have been noted following applications of cyhalothrin in Texas and other states (Kidd et al. 1996). Pyrethroid insecticide applications can be quite detrimental to populations of several species of natural enemies. The disruption of natural enemy populations could partly explain aphid increases. However, aphid populations can be increased on a very small scale by applications of pyrethroids to single plants, which partially negates the effects on mobile predators. 
Aphid populations increased by 7.2 , 32.1 and 57.8 times on untreated, bifenthrin-treated, and cyfluthrintreated plants, respectively, over a 15day period. The nitrogen regime and pyrethroid application also appear to interact synergistically on aphid populations. Naturally occurring aphid populations were monitored in plots in 1999; at the onset of aphid buildup in plots with 20,50,100,150 and 200 pounds nitrogen per acre, an application of either bifenthrin, imidacloprid or no insecticide was superimposed. Three weeks later, in the untreated plots, aphid numbers increased slightly across the increasing nitrogen levels ( 10.9 to 24.8 aphids per leaf from 20 to 200 pounds nitrogen per acre) (fig. 1). Imidacloprid reduced aphid numbers significantly. However, at 20 to 100 pounds nitrogen per acre, the aphid population was $50 \%$ to $75 \%$ higher in the bifenthrin-treated plots compared with untreated and at 150 and 200 pounds nitrogen per acre, there were three and four times, respectively, more aphids in the bifenthrin-treated plots compared with the untreated.

\section{Extension and implementation}

The results from these research projects were extended to the cotton industry in a timely manner. This information was included in the 1996 edition of the UC DANR publication, "IPM for Cotton in the Western United States." Aphid management, sam-

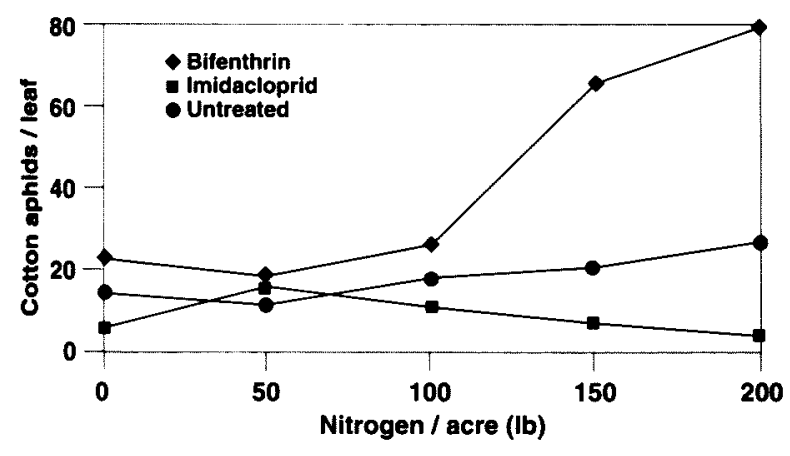

Fig. 1. Cotton aphid populations 3 weeks after insecticide treatment. The $0 \mathrm{lb} / \mathrm{acre}$ treatment had $\sim 20$ lb/acre residual nitrogen in the soil. The other nitrogen treatments were adjusted based on this residual nitrogen. pling, decision guidelines and treatment suggestions were incorporated in the regular revisions of the UC DANR Pest Management Guidelines.

The cotton aphid represents an interesting case in that the severe 1995 outbreak brought the cotton industry - UC scientists, commodity group representatives, growers, pest control advisers, crop protection companies and regulators - together to discuss the situation, plan better, coordinate research among scientists, and dovetail research with grower and pest control adviser observations. A key outcome was the recognition for the need to manage multiple insect pests as a complex, rather than as individual pests. Between 1991 and 1999, we communicated results and suggested modified production practices to growers and pest control advisers through newsletters. Aphid biology and management were discussed during monthly summer production meetings in Kern, Tulare, Kings, Fresno, Madera and Merced counties from 1991 to 2000.

Many growers in the SJV have implemented our recommendations and their management of cotton aphid has improved through a better understanding that a cotton field is a system and that there are significant interactions and linkages among production and pest management practices and resultant arthropod populations (Goodell et al 1997). For instance, insecticide and acaricide usage has declined by about $65 \%$ (pounds of active ingredient applied) and applications per planted acre have declined from 5.7 to 2.8 from 1995 to 1999 , according to California Department of Pesticide Regulation pesticide use reports. There is still an acute need to study why cotton aphid outbreaks occur. Rather than utilizing a therapeutic approach, increased understanding of the ecosystem can help to further minimize populations of this pest and allow continued advancement of cotton IPM.
L.D. Godfrey is Cooperative Extension Specialist, and J.A. Rosenheim is Associate Professor, Department of Entomology, UC Davis; and P.B. Goodell is IPM Entomologist/Nematologist, UC Kearney Agricultural Center, Parlier.

This research has been funded by industry, state and federal sources, including UC Integrated Pest Management Project, Cotton Incorporated State Support and Core budgets, California Crop Improvement Association, Cotton Pest Control Board, California Fertilizer Research and Education Program, and USDA-National Research Initiative.

\section{References}

Cisneros J, Rosenheim JA. 1997. Ontogenetic change of prey preference in the generalist predator Zelus renardii and its influence on predator-predator interactions. Ecological Entomol 22:399-407.

Godfrey LD, Fuson KJ, Wood JP, Wright SD. 1997. Physiological and yield responses of cotton to mid-season cotton aphid infestations in California. Proceedings

Beltwide Cotton Conferences. p 1048-51.

Godfrey LD, Keillor K, Hutmacher RB, Cisneros J. 1999. Interaction of cotton aphid population dynamics and cotton fertilization regime in California cotton. Proceedings Beltwide Cotton Conferences. p 1008-12. Goodell PB, Grafton-Cardwell EE, Godfrey LD. 1997. Maintaining an IPM program in a shifting pest environment. Proceedings Beltwide Cotton Conferences:1146-8.

Grafton-Cardwell EE. 1991. Geographical and temporal variation in response to insecticides in various life stages of Aphis gossypii (Homoptera: Aphididae) infesting cotton in California. J Econ Entomol

84:741-9.

Grafton-Cardwell EE, Godfrey LD, Brindley WA, Goodell PB. 1997. Status of lygus bug and cotton aphid resistance in the San Joaquin Valley. Proceedings Beltwide Cotton Conferences. $p$ 1072-3.

Kidd PW, Rummel DR, Thorvilson HG. 1996. Effect of cyhalothrin on field populations of the cotton aphid. Aphis gossypii Glover in the Texas high plains. Southwest Entomol 21:293-301.

Rosenheim JA, Wilhoit LR, Colfer RG. 1994. Seasonal biology and polymorphism of the cotton aphid, Aphis gossypii in California. Proceedings Beltwide Cotton Conferences. $p$ 125-31.

Rosenheim JA, Wilhoit LR, Goodell PB, et al. 1997. Plant compensation, natural biological control, and herbivory by Aphis gossypii on pre-reproductive cotton: The anatomy of a non-pest. Entomologia Experimentalis et Applicata 85:45-63.

Swift, JE. 1958. Factors influencing the distribution and seasonal abundance of Aphis gossypii Glover in California. Ph.D. Diss., UC Berkeley, 175 p. 